\title{
Potential Nutritional Recommendations and Herb Extracts for Novel COVID-19 Pandemic Infection
}

\author{
Manal Mused Almatrafi ${ }^{1}$ and Rokayya Sami ${ }^{1}$ \\ ${ }^{1}$ Taif University College of Science
}

May 20, 2020

\begin{abstract}
Novel coronavirus (COVID-19) outbreak infections have posed a considerable impendences globally, while millions of infections and thousands of death rates are gradually reported day by day. Due to the instant absence of vaccine, it is extremely necessary to find out unconventional, ecofriendly and effective approaches to control/prevent the further spreading of this serious infection. The present article expresses the potential nutritional recommendations from prevention of novel Covid-19 pandemic infection. It also provides facts about the bioactive ingredients of special supplements, foods and herbs for human immune system reinforcement against the infection.
\end{abstract}

\section{Hosted file}

Editoral.doc available at https://authorea.com/users/324656/articles/452765-potentialnutritional-recommendations-and-herb-extracts-for-novel-covid-19-pandemic-infection 